\title{
Technique: Large-scale ionospheric conductance estimated from combined satellite and ground-based electromagnetic data
}

\author{
D. L. Green, ${ }^{1}$ C. L. Waters, ${ }^{1}$ H. Korth, ${ }^{2}$ B. J. Anderson, ${ }^{2}$ A. J. Ridley, ${ }^{3}$ and R. J. Barnes ${ }^{2}$ \\ Received 12 September 2006; revised 8 November 2006; accepted 20 February 2007; published 12 May 2007.
}

[1] A technique for estimating the large-scale spatial distribution of the height-integrated electrical conductivity (conductance) of the Earth's high-latitude ionosphere is presented. By combining satellite magnetic perturbation data with ground-based magnetometer and HF radar observations the Hall $\left(\Sigma_{\mathrm{H}}\right)$ and Pedersen $\left(\Sigma_{\mathrm{P}}\right)$ conductances are independently calculated. Magnetic perturbations observed at the Earth's surface are combined with those recorded by satellites to calculate the horizontal ionospheric current $\left(\vec{J}_{\perp}\right)$. Combined HF radar and satellite ion drift data give the ionospheric electric field $\left(\vec{E}_{\perp}\right)$, which combined with $\vec{J}_{\perp}$ allows $\Sigma_{\mathrm{H}}$ and $\Sigma_{\mathrm{P}}$ to be estimated from Ohm's law. Conductance results from preliminary application of the technique to an event with a 1 hour integration time are presented. Significant uncertainties arise due to sparse ground magnetometer and electric field coverage. The resulting conductance distribution shows an enhancement in the auroral regions as expected from a statistical model conductance. However, the calculated conductance enhancement is located between the region 1 and region 2 Birkeland currents. This agrees with the statistical model data in the morning sector but disagrees in the evening sector. Comparison of the conductance results with conductance data inferred from in situ precipitating particle observations shows colocated enhancements. The calculated data also show a low $(<1)$ Hall to Pedersen conductance ratio in regions near downward Birkeland current.

Citation: Green, D. L., C. L. Waters, H. Korth, B. J. Anderson, A. J. Ridley, and R. J. Barnes (2007), Technique: Large-scale ionospheric conductance estimated from combined satellite and ground-based electromagnetic data, J. Geophys. Res., 112, A05303, doi:10.1029/2006JA012069.

\section{Introduction}

[2] The solar wind can deliver $\sim 10^{12} \mathrm{~W}$ of power to the Earth's magnetosphere [Waters et al., 2004] and is coupled to the Earth's atmosphere by a system of electrical currents that flow along geomagnetic field lines (Birkeland currents) and close across the high-latitude ionosphere. A critical parameter in this magnetosphere-ionosphere (M-I) circuit is the spatial distribution of electrical conductivity throughout the high-latitude ionosphere which determines the amount of energy deposited into the ionosphere and underlying thermosphere. Since the scale size of altitude variations within the conducting ionosphere are much smaller than those of the M-I circuit, it is convenient to treat the ionosphere as a thin conducting shell described by height-integrated conductivity, hereinafter referred to as conductance.

[3] The lack of any real-time, global model of ionospheric conductance presently hinders attempts to accurately model

\footnotetext{
${ }^{1}$ School of Mathematical and Physical Sciences, University of Newcastle, Callaghan, New South Wales, Australia.

${ }^{2}$ Johns Hopkins University Applied Physics Laboratory, Laurel, Maryland, USA.

${ }^{3}$ University of Michigan, Ann Arbor, Michigan, USA.

Copyright 2007 by the American Geophysical Union. 0148-0227/07/2006JA012069
}

the magnetosphere-ionosphere-thermosphere (M-I-T) system [Brekke and Moen, 1993]. A recent example is presented by Raeder et al. [2001] where the results of a global M-I coupling simulation are shown to critically depend on conductance and they further suggest that agreement between the observed and simulated parameters may be improved using a more realistic auroral conductance model. While the technique presented in this paper is not yet capable of routinely producing real-time conductance estimates, it may be useful in the development of an improved model for the spatial distribution of ionosphere conductance in the auroral zone.

[4] There are two primary sources of ionization and hence electrical conductance in the high-latitude ionosphere. The component due to solar radiation is well understood and may be modelled as a function of solar zenith angle and solar flux [e.g., Rasmussen et al. 1988]. In contrast, spatial variations of the ionospheric conductance in the auroral zones are primarily caused by charged particle precipitation. The geometry of these auroral conductance enhancements are linked to the highly variable magnetosphere, making their distribution difficult to represent in statistical models.

[5] Presently available models for the auroral conductance enhancement are based on time-averaged incoherent HF radar data [e.g., Ahn et al., 1983] or statistical binning of satellite particle data [e.g., Hardy et al., 1987]. However, 
under magnetically active conditions, (e.g., substorms) significant deviations from the time-averaged picture these models provide are possible making them mostly unsuitable for single event studies. Recent efforts to improve estimates of ionospheric conductance by Lummerzheim et al. [1991], Ostgaard et al. [2001], Aksnes et al. [2002, 2005], and Coumans et al. [2004] involve spectral imaging of the ionosphere from space. These approaches calculate the precipitating auroral particle energy spectra from observed ionospheric emissions and an assumed spectral shape. The spectra are used as input to an atmospheric model which estimates the ionospheric effects of energy deposition by energetic particles giving electron density profiles and hence the conductance via theoretical expressions such as those given by Chapman [1956]. The primary advantage of this approach over ground-based radar and single satellite studies is that a global conductance distribution may be estimated with both a temporal resolution of minutes and spatial resolution of several hundred kilometers. However, the complex process and reliance on model data in these methods motivates the investigation into more direct methods. Furthermore, conductance estimates using this approach are limited to available satellite data in the appropriate orbital position for imaging the desired high-latitude region.

[6] This paper presents a more direct approach to calculating the large-scale, spatial distribution of ionospheric conductance by application of Ohm's law to the ionospheric current sheet. The height-integrated horizontal ionospheric current $\left(\vec{J}_{\perp}\right)$ is typically described by equation (1) with Pedersen current in the direction of the ionospheric electric field $\left(\vec{E}_{\perp}\right)$ and Hall current in the direction perpendicular to both $\vec{E}_{\perp}$ and the Earth's geomagnetic field $(\vec{B})$.

$$
\vec{J}_{\perp}=\Sigma_{\mathrm{P}} \vec{E}_{\perp}+\Sigma_{\mathrm{H}} \hat{\vec{B}} \times \vec{E}_{\perp}
$$

$\Sigma_{\mathrm{H}}$ and $\Sigma_{\mathrm{P}}$ are the Hall and Pedersen conductances, respectively. Equation (1) suggests a simple method for calculating ionospheric conductance based on knowledge of $\vec{E}_{\perp}$ and $\vec{J}_{\perp}$. While $\vec{E}_{\perp}$ is available as a standard data product from the Super Dual Auroral Radar Network (SuperDARN), as pointed out by many authors [Bostrom, 1964; Vasyliunas, 1970; Fukushima, 1971, 1976; Untiedt and Baumjohann, 1993], it is not possible to have full knowledge of the total ionospheric current vector $\left(\vec{J}_{\perp}\right)$ based solely on magnetic measurements at the Earth's surface. For complete knowledge of $\vec{J}_{\perp}$, spatially distributed magnetic field measurements from both above and below the ionosphere must be obtained. Without a satellite network capable of providing such measurements or averaging months of single satellite observations, an assumed Hall to Pedersen conductance ratio is required if only $\vec{E}_{\perp}$ and magnetic perturbation data from either above or below the ionosphere are to be used to calculate conductance. This approach was presented by Untiedt [1983] and further developed by Inhester et al. [1992] and Amm [1995] to yield the "JEQ-based Method of Characteristics" and "FAC-based Method of Characteristics" [Amm, 2002]. The "JEQ" approach refers to the use of a current sheet that produces a magnetic perturbation equivalent to that seen on the ground and not the complete $\vec{J}_{\perp}$. The "FAC" approach uses those magnetic perturbations seen by satellites due to the field-aligned currents (FAC). The technique presented here avoids the assumption of a Hall to Pedersen conductance ratio by combining $\vec{E}_{\perp}$ with a complete $\vec{J}_{\perp}$ calculated from global magnetic field perturbation data observed by individual scientific satellites, the Iridium satellite constellation, and ground-based magnetometers.

[7] Our approach is similar to the Elementary Current Method (ECM) presented by Amm [2001] in that the complete, not equivalent, horizontal ionospheric current $\left(\vec{J}_{\perp}\right)$ is derived from combined ground and spacecraft magnetic field data. However, in contrast to Amm [2001], our method is based on spherical cap harmonic analysis (SCHA) [Haines, 1985] and we approach the global problem using experimental data rather than a localized analysis and simulated data. The mathematical framework used to calculate $\vec{J}_{\perp}$ is presented and applied to an example event in sections 2.1 and 2.2. In section 2.3 the ionospheric electric field is estimated from combined SuperDARN and satellite plasma velocity observations. The resulting conductances are presented in section 3 and compared with conductance data from a statistical model and inferred from in situ precipitating particle observations.

\section{Data and Method}

[8] At high latitudes the Earth's geomagnetic field can be assumed to extend radially such that within a heightintegrated ionosphere the horizontal current density for the northern hemisphere is represented using Ohm's law and a tensor conductance as

$$
\vec{J}_{\perp}=\left[\begin{array}{cc}
\Sigma_{\mathrm{P}} & \Sigma_{\mathrm{H}} \\
-\Sigma_{\mathrm{H}} & \Sigma_{\mathrm{P}}
\end{array}\right] \cdot \vec{E}_{\perp}
$$

The Hall and Pedersen conductances can therefore be expressed, according to Amm [2001],

$$
\Sigma_{\mathrm{H}}=\frac{\hat{\vec{r}} \cdot\left(\vec{J}_{\perp} \times \vec{E}_{\perp}\right)}{\left|\vec{E}_{\perp}\right|^{2}} \quad \Sigma_{\mathrm{P}}=\frac{\vec{J}_{\perp} \cdot \vec{E}_{\perp}}{\left|\vec{E}_{\perp}\right|^{2}}
$$

If both $\vec{E}_{\perp}$ and $\vec{J}_{\perp}$ are known, then the Hall and Pedersen conductances may be independently calculated. In this paper the complete $\vec{J}_{\perp}$ is decomposed into two separate vector fields which may be individually recovered from (1) the Birkeland current associated magnetic field perturbations observed by satellites and (2) ground magnetometer data.

[9] The mathematical framework begins with the Helmholtz theorem which allows $\vec{J}_{\perp}$ to be decomposed into curlfree $\left(\mu_{0} \vec{J}_{\mathrm{cf}}=\vec{\nabla}_{1} \mathrm{p}\right)$ and divergence-free $\left(\mu_{0} \vec{J}_{\mathrm{df}}=\vec{r} \times \overrightarrow{\nabla \mathrm{q}}\right)$ components. Using the notation of Backus [1986],

$$
\mu_{0} \vec{J}_{\perp}=\vec{\nabla}_{1} \mathrm{p}+\vec{r} \times \vec{\nabla} \mathrm{q}
$$

where $\vec{\nabla}_{1}=r \vec{\nabla}_{\perp}$ and $p$ and $q$ are the poloidal and toroidal current scalars, respectively. The magnetic perturbations observed on the Earth's surface are due solely to $\vec{J}_{\mathrm{df}}$ [Fukushima, 1976; Untiedt and Baumjohann, 1993], while the magnetic perturbations due to Birkeland currents can be directly related to $\vec{J}_{\text {cf. In the following two sections, global }}$ 
distributions of $p$ and $q$ are independently recovered from satellite and ground magnetometer data.

\section{1. $\vec{J}_{\text {cf }}$ From Iridium, DMSP, and Oersted Data}

[10] The engineering magnetometer data from the Iridium satellite constellation are available for studies of the Birkeland currents [Anderson et al., 2000]. The Iridium satellite constellation is a global network consisting of more than 70 low Earth orbit (LEO, $780 \mathrm{~km}$ ) satellites in six equally spaced polar orbital planes. Magnetometers on board each satellite provide data with an amplitude resolution of $\sim 30 \mathrm{nT}$ which allows extraction of the magnetic perturbation $\left(\vec{b}_{\text {sat }}\right)$ due to Birkeland currents according to the process described by Anderson et al. [2002]. Only the cross-track component of $\vec{b}_{\text {sat }}$ is presently available, as uncertainties in satellite attitude make extracting the small along-track and zenith components difficult. The onboard magnetometer data sample rate is $11 \mathrm{~Hz}$. Since these data are part of satellite housekeeping, the available data are typically one sample every $200 \mathrm{~s}$ [Anderson et al., 2000]. This means that in order to resolve features of the order $3^{\circ}$ in latitude, an integration time of between 45 mins and 2 hours is required.

[11] Since the integration time used in processing the Iridium data can exceed the timescale of significant reconfiguration within the M-I system, it is necessary to ensure that the chosen integration period spans an interval where the system is relatively stable. The data used here for an example application of the presented technique were recorded over $0330-0430$ UT on 1 November 2001. The interplanetary data from the Advanced Composition Explorer (ACE) satellite and SuperDARN ionospheric plasma convection maps were examined for stability over the time period. The upstream solar wind data observed by ACE during the interval $0220-0320$ UT (70 min delay) is shown in Figure 1. Analysis of the parameters showed a relatively constant southward IMF and the following mean characteristics: $B_{\mathrm{x}}=3.6 \pm 0.6 \mathrm{nT}, B_{\mathrm{y}}=-0.6 \pm 0.5 \mathrm{nT}, B_{\mathrm{z}}=-9.1 \pm$ $0.4 \mathrm{nT}, B_{\mathrm{t}}=9.7 \pm 0.3 \mathrm{nT}$, clock angle of $184 \pm 3 \mathrm{deg}, \mathrm{N}_{\mathrm{p}}=$ $5.5 \pm 0.4 \mathrm{~cm}^{-3}, \mathrm{v}_{\mathrm{p}}=359 \pm 3 \mathrm{~km} \mathrm{~s}^{-1}$, and $\mathrm{P}_{\mathrm{dyn}}=1.2 \pm$ $0.1 \mathrm{nPa}$. Throughout the interval the 2-min SuperDARN convection maps showed a typical two cell convection pattern consistent with southward IMF. These are conditions for a stable M-I system over the event interval.

[12] The cross-track magnetic perturbation data from Iridium (black), full-vector data from Defense Meteorological Satellite Program (DMSP) F13 and F15 spacecraft (blue) and the Oersted satellite (red) are shown in Figure 2. Figure 2 and all following polar plots are in the Altitude Adjusted Corrected Geomagnetic (AACGM) [Baker and Wing, 1989; Bhavnani and Hein, 1994] latitudinal and Magnetic Local Time (MLT) coordinate system. The satellite magnetic data are scaled to an ionospheric altitude $\left(R_{\mathrm{i}}\right)$ from the satellite geocentric distance $(r)$ such that $\vec{b}_{\mathrm{i}}=$ $\left(r / R_{\mathrm{i}}\right)^{3 / 2} \vec{b}_{\text {sat }}$. Assuming radial and hence poloidal Birkeland currents, the associated magnetic perturbation may be represented as a toroidal vector field

$$
\vec{b}_{\mathrm{i}}=\vec{r} \times \vec{\nabla} Q
$$

where $Q$ is the toroidal magnetic scalar. It can be shown [Backus, 1986], for a spherical conducting shell enclosing a region where $\vec{\nabla} \times \vec{b}=0$, that $Q=p$. A method for both combining the various sources of $\vec{b}_{\mathrm{i}}$ data and determining $p$, based on the Spherical Cap Harmonic Analysis (SCHA) of Haines [1985], has been presented by Green et al. [2006]. This weighted, multiprecision SCHA fitting process is applied to the $\vec{b}_{\mathrm{i}}$ data according to

$$
\hat{\vec{b}_{\mathrm{i}}} \cdot(\vec{r} \times \overrightarrow{\nabla p})=\sum_{k=1}^{K} \sum_{m=0}^{M \leq k} a_{\mathrm{k}}^{\mathrm{m}} \hat{\vec{b}_{\mathrm{i}}} \cdot\left(\vec{r} \times \vec{\nabla} Y_{\mathrm{n}_{\mathrm{k}}}^{\mathrm{m}}(\theta, \phi)\right)
$$

and

$$
p=\sum_{k=1}^{K} \sum_{m=0}^{M \leq k} a_{\mathrm{k}}^{\mathrm{m}} Y_{\mathrm{n}_{\mathrm{k}}}^{\mathrm{m}}(\theta, \phi)
$$

where $Y_{\mathrm{nk}}^{\mathrm{m}}(\theta, \phi)$ are Spherical Harmonic functions of real degree $n$ and integer order $m$ whose value is zero at the boundary of the spherical cap. The $a_{\mathrm{k}}^{\mathrm{m}}$ coefficient set is calculated using a Singular Value Decomposition (SVD) as described by Press et al. [1986]. Applying the SCHA to a spherical cap of half-angle $40^{\circ}$ with $M=5$ and $K=$ $15\left(n_{15}(0) \approx 61\right)$ gives a minimum latitudinal resolution in the resulting $p$ scalar of $3.1^{\circ}$. Figure 3 shows the reconstructed curl-free ionospheric current $\left(\vec{J}_{\mathrm{cf}}\right)$ and poloidal current scalar $(p)$.

\section{2. $\vec{J}_{d f}$ From Ground-Based Magnetometer Data}

[13] Ground-based magnetometer data are used to estimate $\vec{J}_{\mathrm{df}}$. However, the magnetic field recorded on the ground contains signatures of currents apart from $\vec{J}_{\mathrm{df}}$ and these must be removed. Contributions of sufficient magnitude relevant to this work are the Earth's main field $(\vec{B})$ and the Solar Quiet (Sq) variation. The uncertainty inherent in a global fit to available $\vec{b}_{\mathrm{g}}$ data is large enough such that other magnetic effects, and for latitudes greater than $60^{\circ}$ the $\mathrm{Sq}$ variation, have insufficient magnitude to require removal. The raw magnetometer data were despiked and averaged to 1 min resolution. The quiet day removal was accomplished using a 30 day window centered on the day of interest. A quiet day variation was constructed from the 30 days of data by setting each $1 \mathrm{~min}$ value to the median of the 30 values for that minute in each of the 30 days. For geomagnetic latitudes greater than $60^{\circ}$ the quiet day curve (1440 median values) was smoothed using a boxcar average over a 3 hour window. For geomagnetic latitudes less than $60^{\circ}$ the median value from the 30 days was used as the quiet day. The quiet day curve was removed from the raw data to produce $\vec{b}_{\mathrm{g}}$. While the $\mathrm{Z}$ (radial) component of $\vec{b}_{\mathrm{g}}$ is available, it was not used in the determination of $\vec{J}_{\text {df. The vertical component of }}$ $\vec{b}_{\mathrm{g}}$ may include contributions associated with currents induced in the Earth and while these are likely to be unimportant for the large-scale analysis of slow varying current systems presented here, for most situations in an M-I context the important information is contained within $\vec{b}_{\mathrm{g} \perp}$ [Untiedt and Baumjohann, 1993].

[14] Since $\vec{J}_{\mathrm{df}}$ is toroidal, the magnetic perturbations observed on the Earth's surface due to $\vec{J}_{\mathrm{df}}\left(\vec{b}_{\mathrm{g}}\right)$ can be represented as a poloidal vector field [Backus, 1986]

$$
\vec{b}_{\mathrm{g}}=\vec{\nabla} \times \vec{r} \times \vec{\nabla} P=\frac{1}{r} \nabla_{1}^{2} P \hat{\vec{r}}-\vec{\nabla}_{1}\left(\frac{\partial}{\partial r} P+\frac{P}{r}\right)
$$




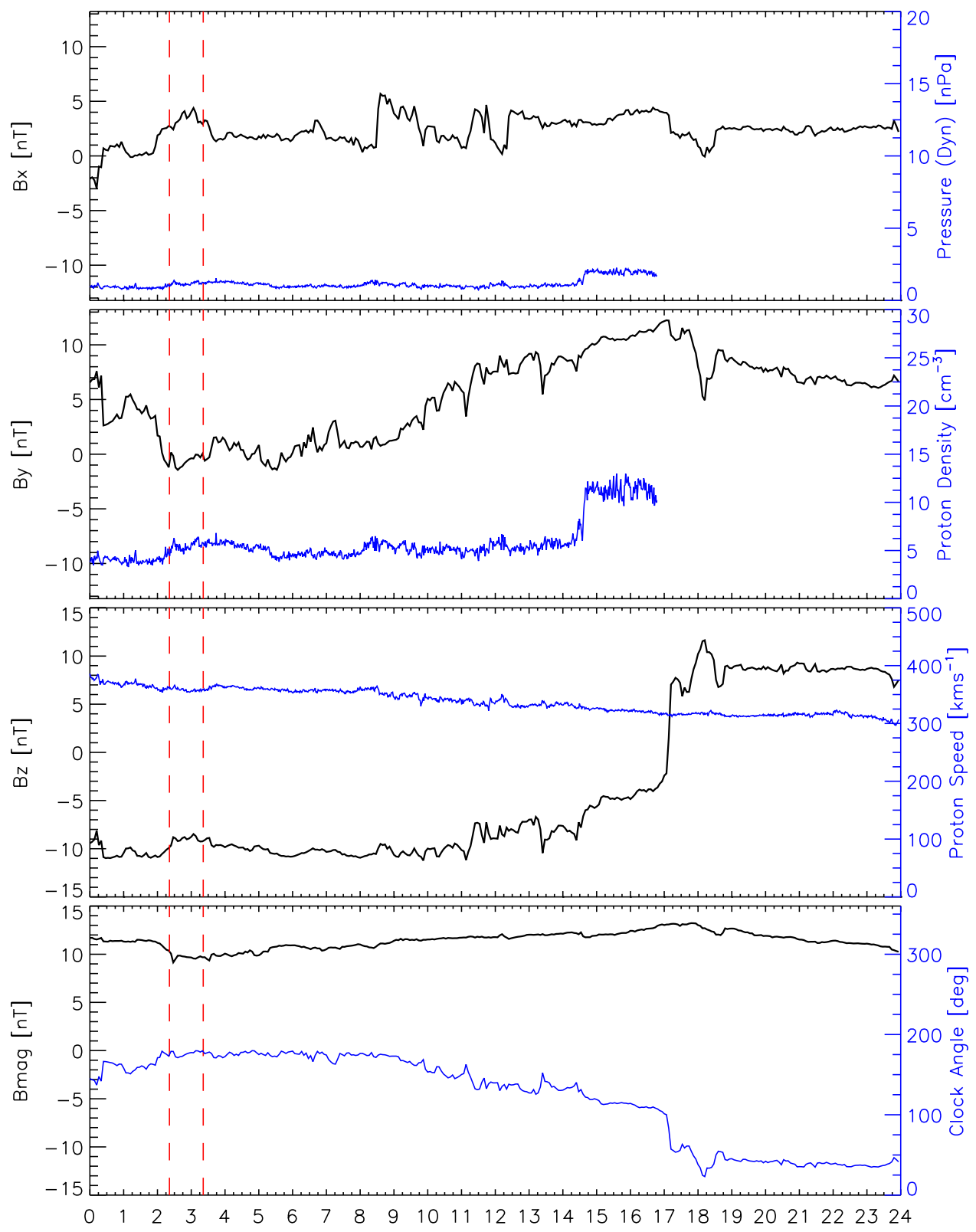

Figure 1. ACE solar wind parameters for 1 November 2001. Dashed lines indicate the conditions at Earth during 0330-0430 UT for a 70 min delay (0220-0320 UT).

where $P$ is the poloidal magnetic scalar. Since $\vec{\nabla} \times \vec{b}_{\mathrm{g}}=0$ the horizontal component of $\vec{b}_{\mathrm{g}}$ may be expressed using Gauss representation as

$$
\vec{b}_{\mathrm{g} \perp}=-\vec{\nabla}_{1}\left(\frac{\partial}{\partial r} P+\frac{P}{r}\right)=-\frac{1}{r} \vec{\nabla}_{1} \psi
$$

where $\psi$ is of similar form to equation (7) and is obtained from $\vec{b}_{\mathrm{g}_{\perp}}$ observations using SCHA. The resulting coefficient set defining $\psi$ is $c_{\mathrm{k}}^{\mathrm{m}}$ which may be used to calculate the toroidal current scalar $(q)$ since the magnetic scalar $(P)$ is directly related to $q$ by

$$
\nabla^{2} P=q
$$

By considering the boundary conditions across the ionospheric current sheet, $q$ at an altitude $R_{\mathrm{i}}$ in terms of $c_{\mathrm{k}}^{\mathrm{m}}$ can be developed as [Chapman and Bartels, 1940; Backus, 1986]

$$
q=-\sum_{k=1}^{K} \frac{\left(2 n_{\mathrm{k}}+1\right)}{\left(n_{\mathrm{k}}+1\right)}\left(\frac{R_{\mathrm{e}}}{R_{\mathrm{i}}}\right)^{1-n_{k}} \sum_{m=0}^{M \leq k} c_{\mathrm{k}}^{\mathrm{m}} Y_{\mathrm{n}_{\mathrm{k}}}^{\mathrm{m}}(\theta, \phi)
$$

A similar expression was used by Engels and Olsen [1998] for the reverse problem of calculating the magnetic field associated with ionospheric currents.

[15] We have shown how a global $\vec{J}_{\text {df }}$ can be found from observations of $\vec{b}_{\mathrm{g}}$ using SCHA. However, observations of $\vec{b}_{\mathrm{g}_{\perp}}$ are not globally available and so estimates of $\vec{J}_{\mathrm{df}}$ in regions lacking experimental data are only constrained by 


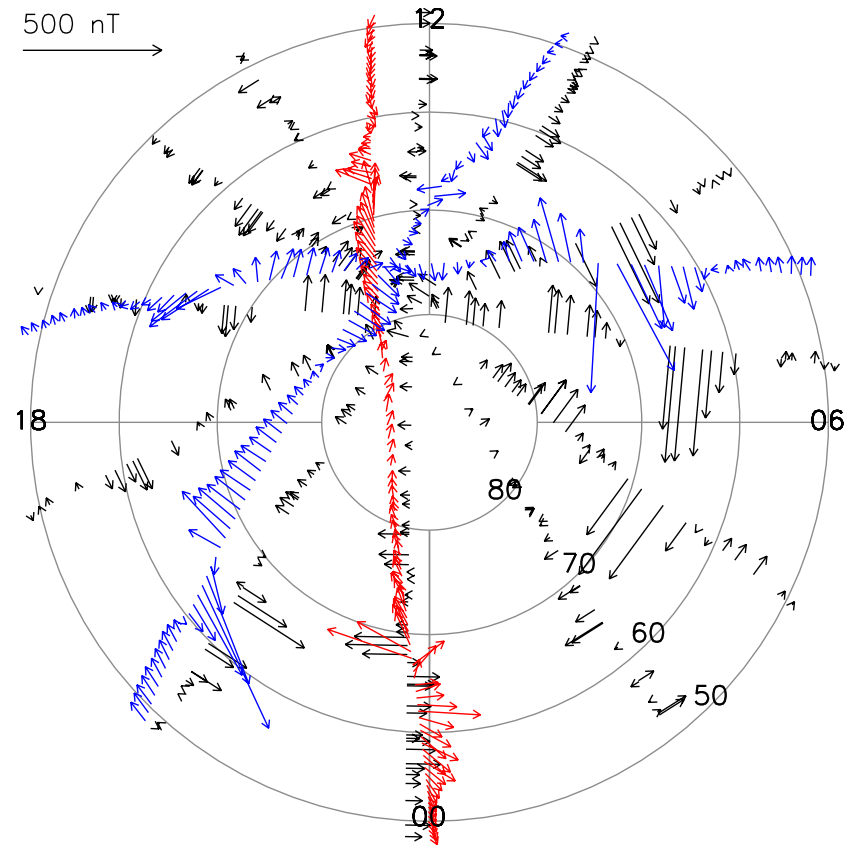

Figure 2. Cross-track component of the Iridium $\vec{b}_{\text {sat }}$ data (black) for 1 November 2001, 0330-0430 UT. The two blue tracks are full vector $\vec{b}_{\text {sat }}$ observations from DMSP satellite F13 (17-07 MLT track) and F15 for 0328-0357 UT and 0351-0422 UT, respectively. The red track shows full vector $\vec{b}_{\text {sat }}$ observations from the Oersted satellite for 0339-0408 UT. Latitudinal coordinates are in the AACGM system.

the condition that the spherical harmonics satisfy Laplace's equation, i.e., $\vec{\nabla} \cdot \vec{b}_{\mathrm{g}}=\vec{\nabla} \times \vec{b}_{\mathrm{g}}=0$. Figure 4 shows available $\vec{b}_{\mathrm{g}_{\perp}}$ data for this event. The observed $\vec{b}_{\mathrm{g}_{\perp}}$ data was modelled using SCHA with $\mathrm{K}=9$ and $\mathrm{M}=6$ (latitudinal resolution of $\sim 6.4^{\circ}$ ). The low order chosen here reflects the problems

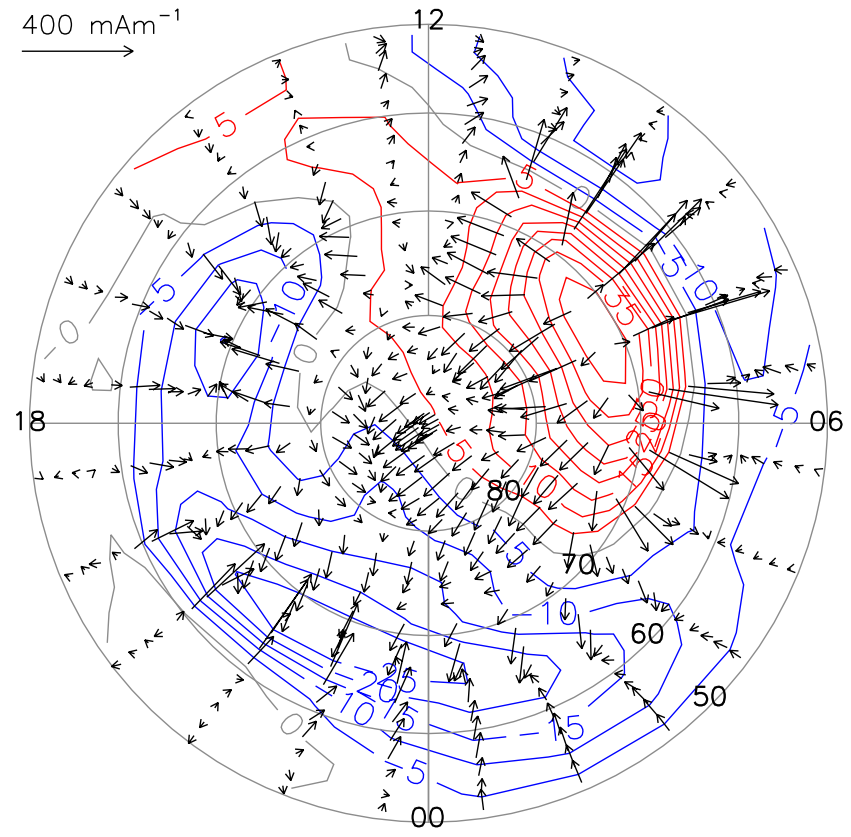

Figure 3. $\vec{J}_{\text {cf }}$ vectors calculated from data in Figure 2. Contours represent $p$ in units of nT.

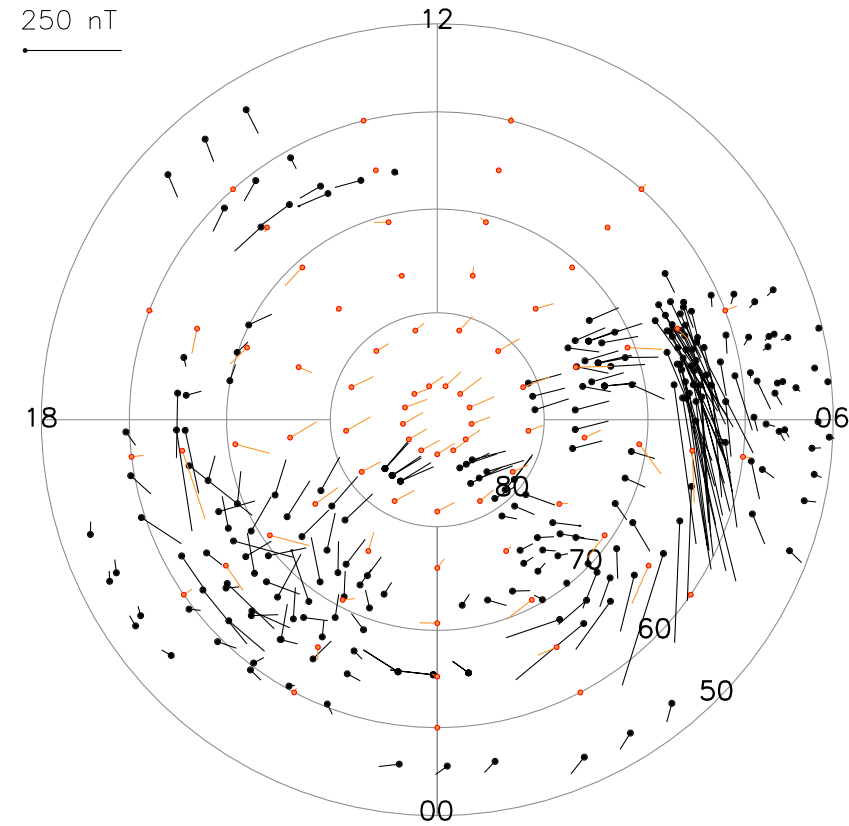

Figure 4. Observations of $\vec{b}_{\mathbf{g}_{\perp}}$ (black) sampled at $30 \mathrm{~min}$ during the 0330-0430 UT interval on 1 November 2001. Model $\vec{b}_{\mathbf{g}_{\perp}}^{\text {mod }}$ data are shown in orange. Vectors are rotated $90^{\circ}$ clockwise to indicate the direction of $\vec{J}_{\mathrm{df}}$.

when modelling sparse and unevenly spaced data with global basis functions. Although a solution to this problem is given in the following paragraph, in future the use of a wavelet basis function approach for modelling both the $\vec{b}_{\mathrm{g}_{1}}$ and SuperDARN data will be investigated. Such basis functions, e.g., the Spherical Elementary Current Systems (SECS) used by Amm [2001], allow a finer representation of the observed data in regions of dense coverage without becoming unstable in regions of sparse coverage.

[16] In regions lacking experimental ground data, the SCHA may suffer aliasing, contaminating estimates for

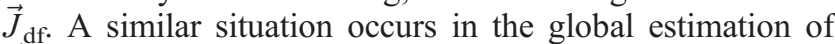
$\vec{E}_{\perp}$ using the SuperDARN data where a statistical model is used to constrain the process. For the ground data we have adopted a similar approach. Additional estimates for ground magnetic data are obtained from $\vec{E}_{\perp}$ and a model conductance. Briefly, the procedure is as follows: (1) a model conductance from EUV [Rasmussen et al., 1988] and particle precipitation [Hardy et al., 1987] contributions is calculated, (2) using $\vec{E}_{\perp}$ from SuperDARN, a model ionospheric current, $\vec{J}_{\perp}^{\text {mod }}$ is computed from equation (2), (3) $\vec{J}_{\perp}^{\text {mod }}$ is separated into $\vec{J}_{\mathrm{cf}}^{\text {mod }}$ and $\vec{J}_{\mathrm{df}}^{\text {mod }}$, and (4) using essentially the reverse of the SCHA process described above, $\vec{J}_{\mathrm{df}}^{\text {mod }}$ is used to provide $\vec{b}_{\mathrm{g}_{\perp}}^{\text {mod }}$. Figure 4 shows $\vec{b}_{\mathrm{g}}^{\text {mod }}$ (orange) sampled at sufficient locations to constrain the global $\vec{J}_{\text {df }}$ according to the Nyquist condition of the shortest wavelength Spherical Harmonic used in the fitting process. The SCHA process applied to $\vec{b}_{\mathrm{g}_{\perp}}$ and $\vec{b}_{\mathrm{g}_{\perp}}^{\text {mod }}$ weighted the model data relative to $\vec{b}_{\mathrm{g}_{\perp}}$ by increasing the weighting linearly with distance from the nearest $\vec{b}_{\mathrm{g}_{\perp}}$ observation. In this way the calculated $\vec{J}_{\mathrm{df}}$ is constrained in regions lacking observation, with little dependence on model data in regions 


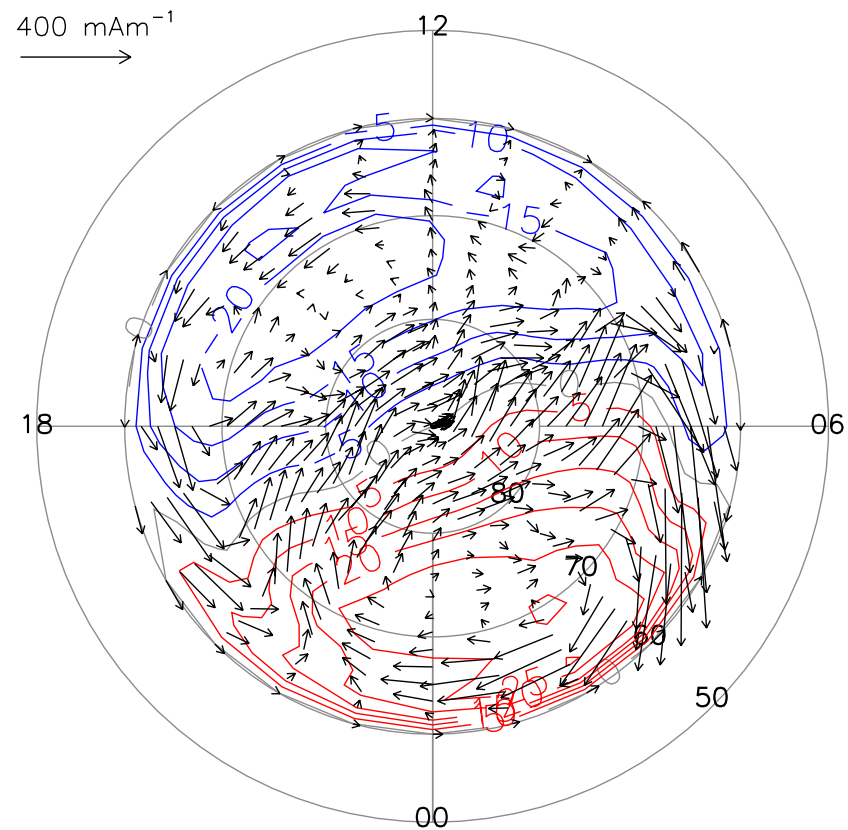

Figure 5. $\quad \vec{J}_{\mathrm{df}}$ vectors calculated from the data in Figure 4. Contours represent $q$ in units of nT.

where experimental data are available. The resulting $\vec{J}_{\mathrm{df}}$ and $q$ for this event are shown in Figure 5.

\section{3. $\quad \vec{E}_{\perp}$ From Combined SuperDARN and DMSP Data}

[17] SuperDARN measures line-of-sight plasma convection velocities, $\vec{v}=\vec{E}_{\perp} \times \vec{B} / B^{2}$, in the F-region ionosphere with respect to the Earth's geomagnetic field $(\vec{B})$, allowing $\vec{E}_{\perp}$ to be estimated [Greenwald et al., 1995] in the Earth reference frame. Depending on geomagnetic activity, velocity measurements span $10-60 \%$ of the probed region [Greenwald et al., 1995] with a model ionospheric potential (RG96 or RG05) [Ruohoniemi and Greenwald, 1996, 2005] used to constrain the construction of a global $\vec{E}_{\perp}$ using Spherical Harmonic Analysis (SHA) [Ruohoniemi and Baker, 1998]. The 2 min $\vec{E}_{\perp}$ maps produced from SuperDARN observations are here averaged over the integration time required by Iridium to reliably estimate the Birkeland current distribution (1 hour). Also, since the radars rotate with the Earth, prior to the construction of $\vec{E}_{\perp}$ the projection of the radar velocity in the line-of-sight direction is subtracted from the plasma velocity observations such that the resultant $\vec{E}_{\perp}$ is in an Earth-centered nonrotating frame of reference. It should be noted that for highly disturbed magnetic conditions the HF signal suffers strong absorption in the lower $\mathrm{E}$ and $\mathrm{D}$ regions of the ionosphere [Ruohoniemi and Greenwald, 1997]. This effectively prohibits the use of this technique to calculate reliable conductance data under highly disturbed conditions since $\vec{E}_{\perp}$ will consist largely of model data. The averaged SuperDARN $\vec{E}_{\perp}$ and electric potential are shown for this event in Figure 6.

[18] To further reduce the dependence on model data, the SuperDARN $\vec{E}_{\perp}$ data are here supplemented with electric field data derived from DMSP ion drift meter observations $\left(\vec{E}_{\perp}^{\mathrm{DMSP}}\right.$ ). Figure 6 shows $\vec{E}_{\perp}^{\mathrm{DMSP}}$ (green) overlayed on the time-averaged SuperDARN $\vec{E}_{\perp}$. The equatorward SuperDARN convection zone boundary (SCZB, thin black line) used in the SuperDARN fitting process is also shown. The location of this boundary is calculated to include all radar observations of significant magnitude [Sheperd and Ruohoniemi, 2000]. Equatorward of this boundary the model ionospheric electric potential used to constrain the fitting process is set to zero. The combination of SuperDARN model and experimental data in the fitting procedure gives small $\left(<1 \mathrm{mVm}^{-1}\right)$ electric field values equatorward of the boundary. However, comparison of $\vec{E}_{\perp}$ and $\vec{E}_{\perp}^{\mathrm{DMSP}}$ reveals the following unrealistic $\vec{E}_{\perp}$ values in the SuperDARN estimate due to a lack of radar returns: (1) Near $70^{\circ}$ and 0900 MLT the SuperDARN $\vec{E}_{\perp}$ shows small magnitude vectors reducing to zero equatorward of the SCZB. The $\vec{E}_{\perp}^{\text {DMSP }}$ vectors here are large in magnitude and show a convection reversal. This suggests that for this case the SCZB should be located further equatorward. (2) Where F15 crosses the SCZB (2030 MLT) $\vec{E}_{\perp}^{\text {DMSP }}$ shows larger magnitudes compared with $\vec{E}_{\perp}$. Therefore adjusting $\vec{E}_{\perp}$ to be more consistent with $\vec{E}_{\perp}^{\mathrm{DMSP}}$ in these regions should improve the reliability of resulting conductance data.

[19] A statistical study by Drayton et al. [2005] compared the cross-track ion drift data from 209 DMSP satellite passes with SuperDARN observed line-of-sight velocities which showed good overall agreement although the SuperDARN observed velocities were slightly smaller. Drayton et al. [2005] also suggested that radar and satellite data could be merged into a common data set under the conditions of smooth convection variations. In this paper an improved electric potential and field are created using the same weighted spherical harmonic fit procedure that was used to combine the DMSP, Oersted, and Iridium magnetic field

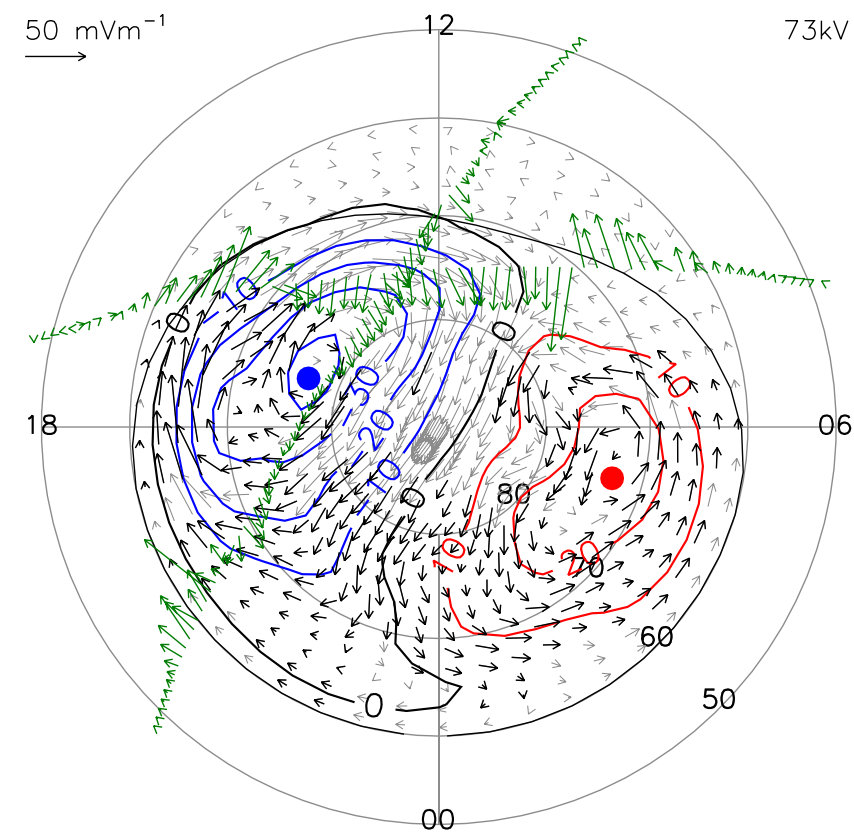

Figure 6. 1 November 2001 0330-0430 UT: SuperDARN global $\vec{E}_{\perp}$ (grey vectors) with black vectors indicating where radar observations exist. DMSP satellite F13 (1700-0700 MLT track, 0328-0357 UT) and F15 (0351-0422 UT) electric field vectors (green) are also shown. The solid black line represents the SCZB. Contour units are $\mathrm{mVm}^{-1}$. All vectors are rotated $90^{\circ}$ counter clockwise to indicate the direction of plasma flow. 


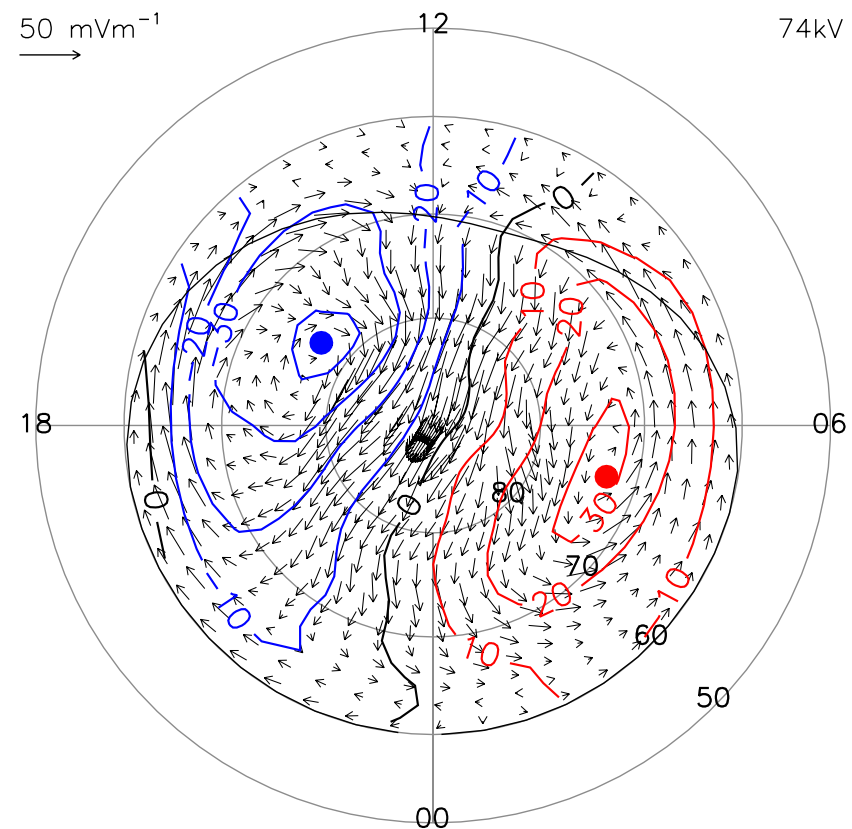

Figure 7. Electric field (rotated by $90^{\circ}$ counter clockwise) resulting from the merging of $\vec{E}_{\perp}$ and $\vec{E}_{\perp}^{\mathrm{DMSP}}$ data in Figure 6.

data. The results of merging $\vec{E}_{\perp}$ and $\vec{E}_{\perp}^{\mathrm{DMSP}}$ are shown in Figure 7.

\section{Results and Discussion}

[20] The addition of $\vec{J}_{\text {cf }}$ (Figure 3) and $\vec{J}_{\text {df }}$ (Figure 5) gives the complete $\vec{J}_{\perp}$ shown in Figure 8 . This $\vec{J}_{\perp}$ is combined with the electric field in Figure 7 using equation (2) to yield the Hall and Pedersen conductances shown in Figures 9 and 10. For comparison, these figures include

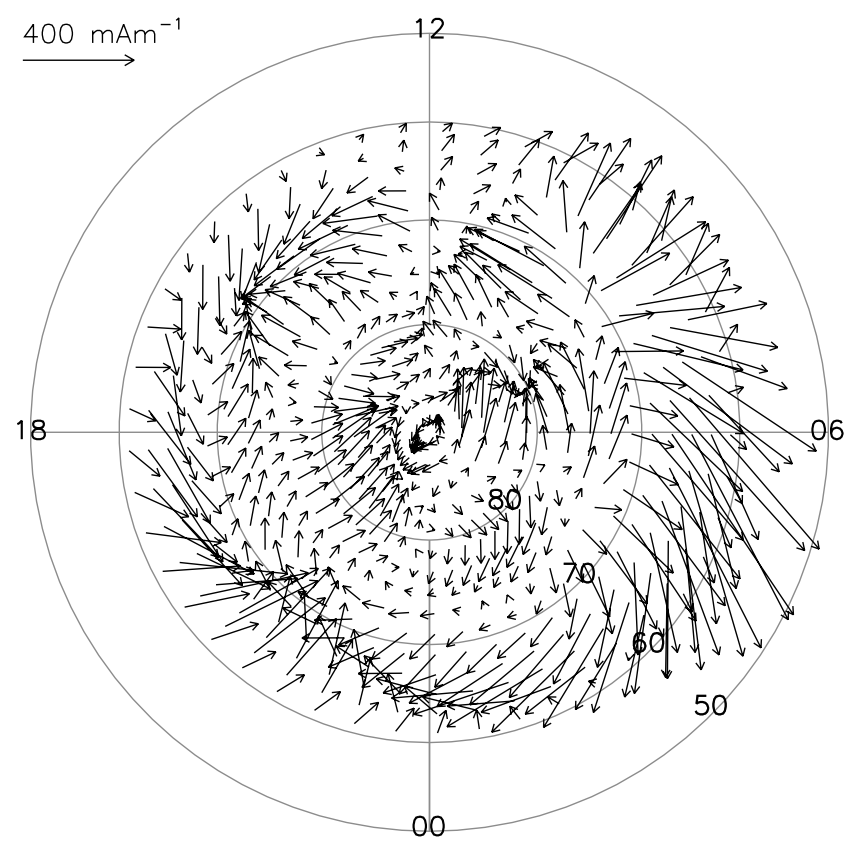

Figure 8. $\quad \vec{J}_{\perp}$ constructed from the addition of $\vec{J}_{\text {df }}$ (Figure 5) and $\vec{J}_{\text {cf }}$ (Figure 3 ).

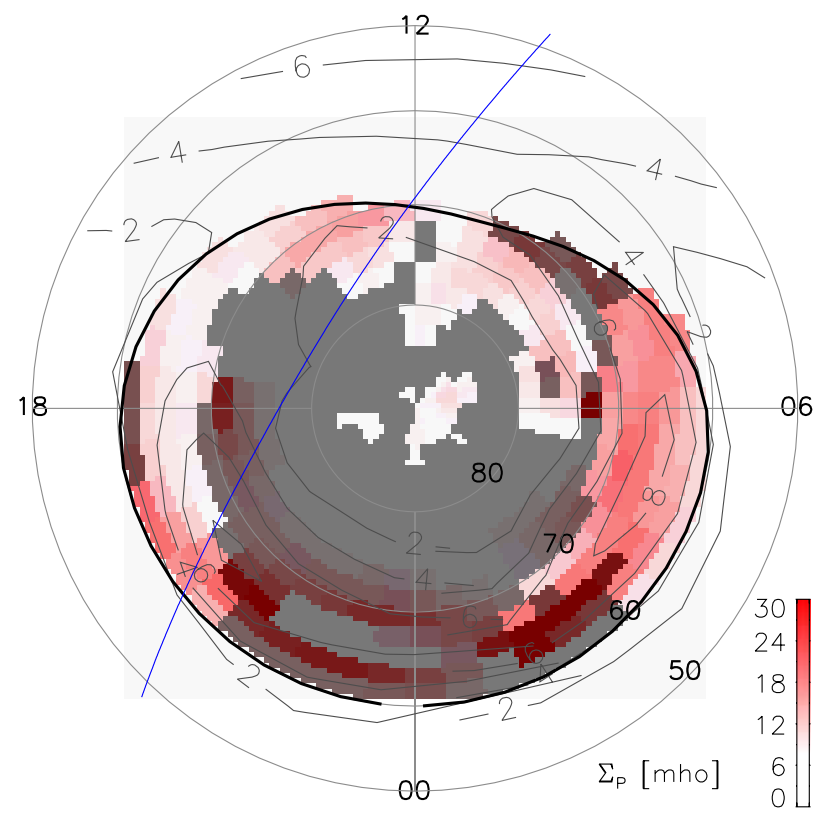

Figure 9. Pedersen conductance calculated from $\vec{J}_{\perp}$ (Figure 8) and $\vec{E}_{\perp}$ (Figure 7) for 1 November 2001 0330-0430 UT. Model conductance contours are overlayed. The blue line indicates the path of the F15 DMSP satellite. Grey masking indicates regions of high uncertainty due to variability in the time-averaged electric field.

contours obtained from the statistical conductance model discussed in section 2 used to calculate $\vec{b}_{\mathrm{g}_{\perp}}^{\text {mod }}$.

[21] Since equation (3) $\left|\vec{E}_{\perp}\right|$ in the denominator, small values for $\left|\vec{E}_{\perp}\right|$ may produce unreasonable conductance

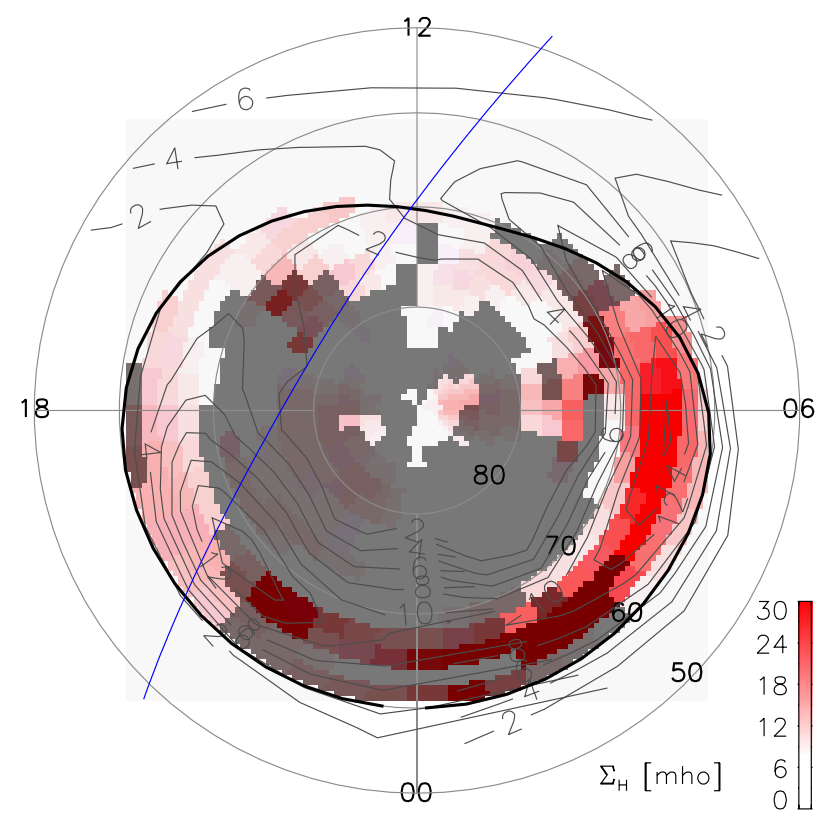

Figure 10. Hall conductance calculated from $\vec{J}_{\perp}$ (Figure 8) and $\vec{E}_{\perp}$ (Figure 7) for 1 November $20010330-0430$ UT. Model conductance contours are overlayed. The blue line indicates the path of the F15 DMSP satellite. Grey masking indicates regions of high uncertainty due to variability in the time-averaged electric field. 


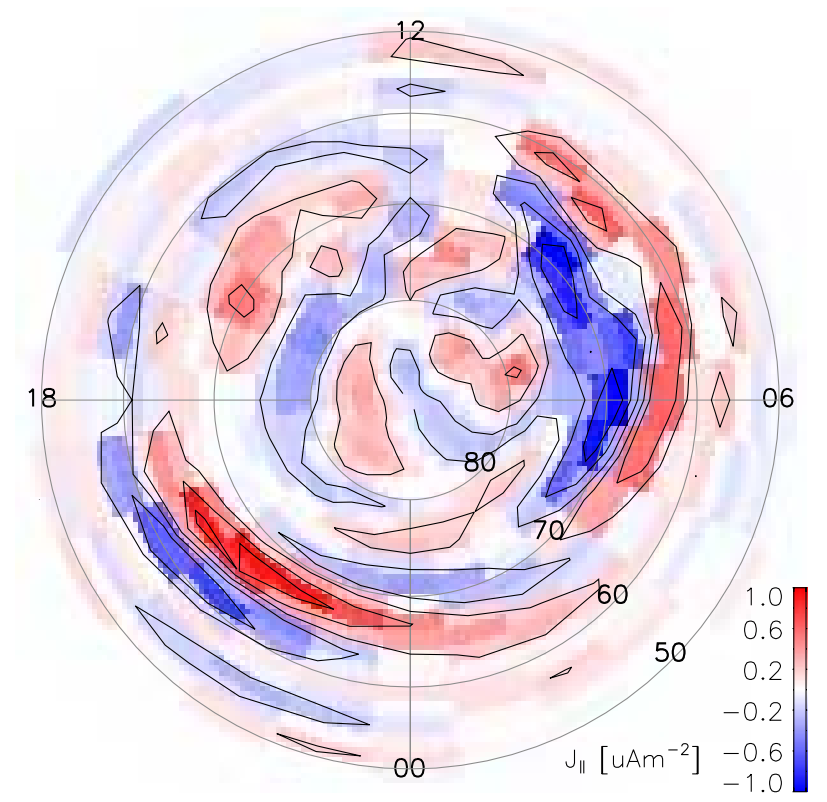

Figure 11. 1 November $20010330-0430$ UT: Birkeland currents derived from the data in Figure 2.

values. Therefore conductance estimates equatorward of the SCZB are ignored. The uncertainty in $\vec{E}_{\perp}$ was estimated by examining the variability in vector direction of the 2-min electric field maps during the 1 hour integration period. Regions where the standard deviation of vector direction was more than $45^{\circ}$ are masked. Furthermore, the root-meansquare (RMS) of differences between the observed DMSP electric field data (green vectors; Figure 6) and the merged $\vec{E}_{\perp}$ fit (Figure 7) evaluated at the DMSP locations is $\sim 10 \mathrm{mVm}^{-1}$. This value gives another measure of the uncertainty in the $\vec{E}_{\perp}$ data so regions where $\left|\vec{E}_{\perp}\right|<10 \mathrm{mVm}^{-1}$ are also masked.

[22] The Hall and Pedersen conductances calculated from $\vec{E}_{\perp}$ and $\vec{J}_{\perp}$ show the expected conductance enhancements in the auroral zones with large values on the nightside and smaller values in the polar cap. In regions constrained by the experimental data, the calculated conductances are expected to be representative of actual values. This includes the regions between $60^{\circ}$ and $70^{\circ}$ from 0300 to 0700 MLT. Reasonable agreement with the model conductance contours is seen from 0300 MLT, anticlockwise through to the SCZB. The estimates are not expected to be identical due to the statistical nature of the conductance model. Both the Hall and Pedersen conductances show a peak near $65^{\circ}$ at 0600 MLT which corresponds with the region between region 1 and region 2 Birkeland currents seen in Figure 11. These Birkeland currents were calculated from the data in Figure 2 using the method presented by Green et al. [2006].

[23] Another region where the conductances are expected to be representative of actual values is between $63^{\circ}$ and $70^{\circ}$ from 1600 to 2200 MLT. Here the calculated conductances disagree with the model contours. As with the morning sector, the calculated conductance enhancement for both Hall and Pedersen values is located between the region 1 and region 2 Birkeland currents shown in Figure 11. The model conductance contours show an enhancement $\sim 4^{\circ}$ poleward of this. Since DMSP F15 traverses this region the conductances calculated from electromagnetic data can be compared with those estimated from low-pass filtered particle data. The particle precipitation induced conductance $\left(\sum_{\mathrm{PP}}^{\mathrm{DMPP}}\right)$ was calculated from both electron and proton particle data using the expressions given by Hardy et al. [1987] and Galand and Richmond [2001], respectively. The particle-induced conductance was combined with the EUV conductance $\left(\sum_{\mathrm{EUV}}^{\mathrm{DMSP}}\right)$ model of Rasmussen et al. [1988] according to $\Sigma^{\mathrm{DMSP}}=\sqrt{\sum_{\mathrm{PP}}^{\mathrm{DPSP}^{2}}+\Sigma_{\mathrm{EUV}}^{\mathrm{DMSP}}}$. Figure 13 compares the resulting conductance data (black) with those derived from electromagnetic data (red) and the conductance model described in section 2 (green). The Pedersen conductance calculated from electromagnetic data (red; left-hand panel) shows agreement with $\sum_{\mathrm{P}}^{\mathrm{DMSP}}$ (black; left-hand panel). The calculated Hall conductance (red; right-hand panel) shows an enhancement colocated with the $\Sigma_{\mathrm{H}}^{\mathrm{DMSP}}$ enhancement (black; right-hand panel). However, the magnitudes are quite different.

[24] While $\Sigma^{\text {DMSP }}$ is based on high spatial resolution particle observations, the expressions presented by Hardy et al. [1987] from which they are calculated depend on empirical fits to 15 months of satellite particle observations [Hardy et al., 1985]. Furthermore, the expressions presented by Hardy et al. [1987] assume a fixed functional relationship between the Hall and Pedersen conductances giving a Hall to Pedersen conductance ratio $\left(\alpha=\Sigma_{\mathrm{H}} / \Sigma_{\mathrm{P}}\right)$ greater than 1 when the average electron energy exceeds $\sim 3.6 \mathrm{keV}$. The method presented in this paper assumes nothing about this ratio. Figure 12 shows the spatial distribution of $\alpha$ was calculated from the conductance data in Figures 9 and 10. These results show $0.3<\alpha<3.3$ in the morning sector and $0.4<\alpha<5.8$ in the evening sector. The evening sector range of $\alpha$ values is different to the constant $\alpha \sim 3$ suggested by the conductances calculated from DMSP

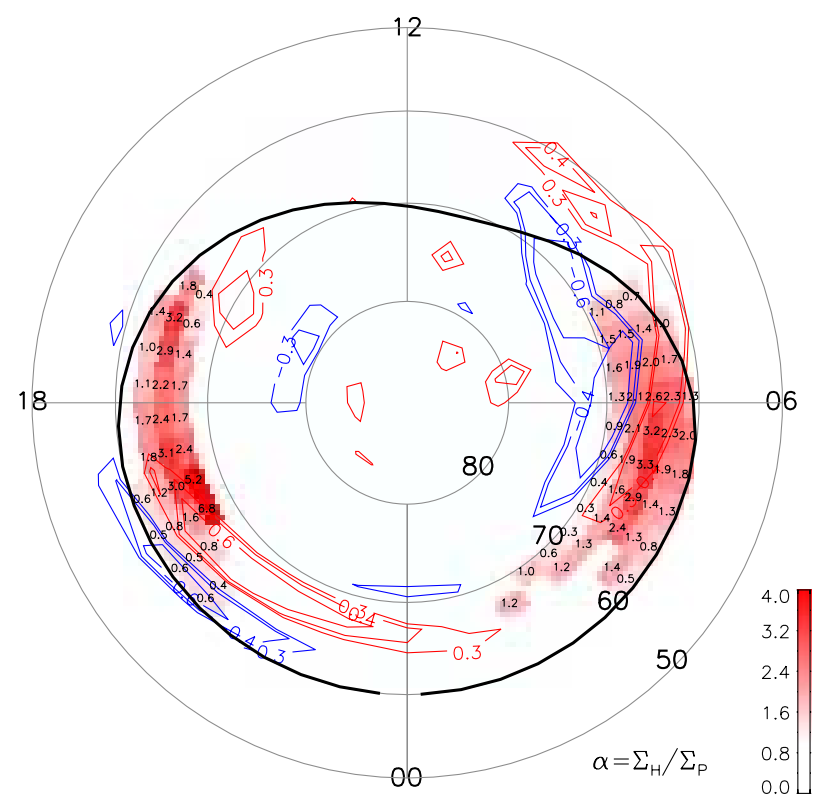

Figure 12. Hall to Pedersen conductance ratio derived from Figures 9 and 10. Values are only shown where electromagnetic observables have significant magnitudes and variability in the time averaged electric field is low. Birkeland current contours from Figure 11 are overlayed. 


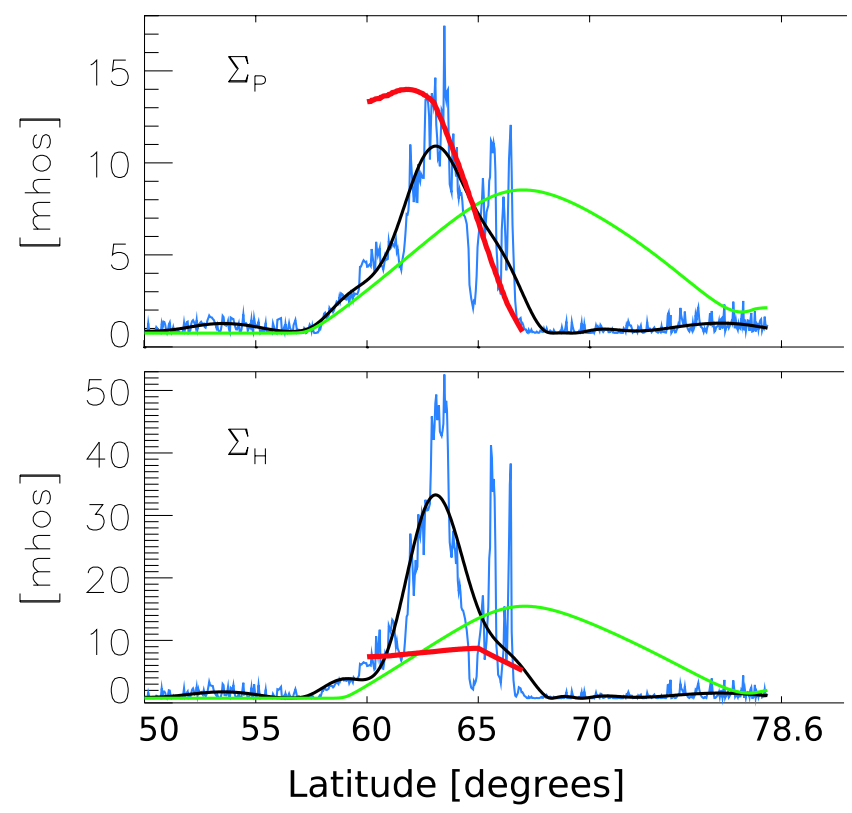

Figure 13. Conductance data along the F15 DMSP track (2100 to 1100 MLT, cf., Figures 9 and 10; 0251:0422 UT). $\Sigma^{\text {DMSP }}$ (raw: blue; filtered: black), conductance model (green) and calculated from electromagnetic data (red).

particle data (black curves; Figure 13). In both morning and evening sectors Figure 12 shows the conductance ratio decreasing below 1 near regions of downward FAC. It has been shown by Aksnes et al. [2002] that the conductance ratio has a spatial variation throughout the auroral zone. Their results indicate for regions of maximum conductance $1.8<\alpha<3.1$. While the time average picture of the Hall to Pedersen conductance ratio is known to be typically greater than 1 , the spatial distribution of $\alpha$ for individual events is yet to be completely understood. For example, Ostgaard et al. [1999] studied the development of the UV and X-ray aurora during 14 isolated substorm events. The results showed that the UV-aurora tended to brighten in the duskward part of the auroral bulge, while the X-ray aurora moved dawnward. The UV-emissions are most reflective of the Pedersen conductance while X-ray aurora are important for the Hall conductance [Aksnes et al., 2004]. Therefore the results by Ostgaard et al. [1999] indicate regions of $\alpha<1$ may be found in the evening sector for active conditions. Even though both the electric and magnetic field observations are supplemented by DMSP in the evening sector where ground magnetometer is also present, it is possible due to uncertainties associated with the fitting process that some part of the Hall current has been interpreted as Pedersen current resulting in the low $\alpha$ values. This possibility is further supported since inspection of the precipitating electron energy spectrum does not show the large low-energy population and high-energy cutoff expected to accompany such low $\alpha$ values.

\section{Conclusions}

[25] A method for calculating the large-scale spatial distribution of the ionospheric Hall $\left(\Sigma_{\mathrm{H}}\right)$ and Pedersen $\left(\Sigma_{\mathrm{P}}\right)$ conductance from electromagnetic data has been described.
The resulting global conductance distribution was compared with an empirical model and conductance data derived from in situ satellite particle data yielding significant similarities. The temporal resolution of this method is presently limited to $\sim 1$ hour by the available sample rate of Iridium magnetic field data. Variability in the electric field during this interval showed that conductance estimates using this technique in all but those regions with significant magnitude electromagnetic observations have a large uncertainty. Also, the sparse nature of ionospheric electric field data, and more so the ground magnetometer data, requires model data to constrain the global analysis. However, in regions constrained by experimental data the Hall and Pedersen conductances have been derived independently with the results expected to represent actual values.

[26] The results obtained by our technique for the event presented show conductance enhancements located between the region 1 and region 2 Birkeland current systems in agreement with a two-dimensional study of auroral zone currents presented by Baumjohann et al. [1980]. The results also show low $(<1)$ Hall to Pedersen conductance ratios near downward Birkeland current in both the morning and evening sectors. These results highlight the need for further investigation into the spatial distribution of the Hall to Pedersen conductance ratio and the location of conductance enhancements relative to the Birkeland current structure. A definitive relationship between conductance enhancement location and Birkeland currents would be invaluable since the Birkeland current distribution are be routinely calculated from Iridium data.

[27] Acknowledgments. We thank Iridium Satellite LLC for providing the engineering magnetometer data, the ACE team for the solar wind data, Fred Rich for providing the DMSP magnetometer data, and Mark Hairston for the DMSP particle data. The Oersted magnetometer data was kindly made available by Freddy Christiansen. Support for analysis of the Iridium data was provided by NSF grants ATM-0334668 and ATM0101064. Ground magnetometer data were made available by CANOPUS (Canadian Space Agency), IMAGE (Finnish Meteorological Institute), Measure (University of California Los Angles), Greenland coastal chains (Danish Meteorological Institute), MAGIC (University of Michigan), MACCS (Augsburg and Boston University), 210 magnetic meridian (Kyushu University and Nagoya University), and Intermagnet.

[28] Zuyin Pu thanks the reviewers for their assistance in evaluating this paper.

\section{References}

Ahn, B.-H., R. M. Robinson, Y. Kamide, and S.-I. Akasofu (1983), Electric conductivities, electric fields and auroral particle energy injection rate in the auroral ionosphere and their empirical relations to the horizontal magnetic disturbances, Planet. Space Sci., 31(6), 641-653.

Aksnes, A., J. Stadsnes, J. Bjordal, N. Østgaard, R. R. Vondrak, D. L. Detrick, T. J. Rosenberg, G. A. Germany, and D. Chenette (2002), Instantaneous ionospheric global conductance maps during an isolated substorm, Ann. Geophys., 20(8), 1181-1191.

Aksnes, A., J. Stadsnes, N. Østgaard, R. R. Vondrak, D. L. Detrick, T. J. Rosenberg, G. A. Germany, and M. Schulz (2004), Effects of energetic electrons on the electrodynamics in the ionosphere, Ann. Geophys., 22(2), $475-496$.

Aksnes, A., O. Amm, J. Stadsnes, N. Østgaard, G. A. Germany, R. R. Vondrak, and I. Sillanpaa (2005), Ionospheric conductances derived from satellite measurements of auroral UV and X-ray emissions, and ground-based electromagnetic data: A comparison, Ann. Geophys., 23(2), 343-358.

Amm, O. (1995), Direct determination of the local ionospheric Hall conductance distribution from two-dimensional electric and magnetic field data: Application of the method using models of typical ionospheric electrodynamic situations, J. Geophys. Res., 100(A11), 21,473-21,488.

Amm, O. (2001), The elementary current method for calculating ionospheric current systems from multisatellite and ground magnetometer data, J. Geophys. Res., 106(A11), 24,843-24,856. 
Amm, O. (2002), Method of characteristics for calculating ionospheric electrodynamics from multisatellite and ground-based radar data, J. Geophys. Res., 107(A10), 1270, doi:10.1029/2001JA005077.

Anderson, B. J., K. Takahashi, and B. A. Toth (2000), Sensing global Birkeland currents with Iridium ${ }^{\mathbb{R}}$ engineering magnetometer data, Geophys. Res. Lett., 27(24), 4045-4048

Anderson, B. J., K. Takahashi, T. Kamei, C. L. Waters, and B. A. Toth (2002), Birkeland current system key parameters derived from Iridium observations: Method and initial validation results, J. Geophys. Res., 107(A6), 1079, doi:10.1029/2001JA000080.

Backus, G. (1986), Poloidal and toroidal fields in geomagnetic field modeling, Rev. Geophys., 24(1), 75-109.

Baker, K. B., and S. Wing (1989), A new magnetic coordinate system for conjugate studies at high latitudes, J. Geophys. Res., 94, 9139-9243.

Baumjohann, W., J. Untiedt, and R. A. Greenwald (1980), Joint twodimensional observations of ground magnetic and ionospheric electric fields associated with auroral zone currents: 1 . Three-dimensional current flows associated with a substorm-intensified eastward elecroject, J. Geophys. Res., 85, 1963-1978.

Bhavnani, K. H., and C. A. Hein (1994), An improved algorithm for computing altitude dependent corrected geomagnetic coordinates, Tech. Rep. $P L-T$ - 94-2310, Phillips Laboratory, Hanscom AFB, Mass.

Bostrom, R. (1964), A model of the auroural electrojets, J. Geophys. Res., $69,4983$.

Brekke, A., and J. Moen (1993), Obseravtions of high latitude ionospheric conductances, J. Atmos. Terr. Phys., 55(11/12), 1493-1512.

Chapman, S. (1956), The electrical conductiivty of the ionosphere: a review., Nuovo Cimento, 4, 1385-1412.

Chapman, S., and J. Bartels (1940), Geomagnetism, Oxford Univ. Press, New York.

Coumans, V., J.-C. Gérard, B. Hubert, M. Meurant, and S. B. Mende (2004) Global auroral conductance distribution due to electron and proton precipitation from IMAGE-FUV observations, Ann. Geophys., 22, 1595-1611.

Drayton, R. A., A. V. Koustov, M. R. Hairston, and J.-P. Villain (2005), Comparison of DMSP cross-track ion drifts and SuperDARN line-ofsight velocities, Ann. Geophys., 23(7), 2479-2486.

Engels, U., and N. Olsen (1998), Computation of magnetic fields within source regions of ionospheric and magnetospheric currents, J. Atmos. Sol. Terr. Phys., 60(16), 1585-1592.

Fukushima, N. (1971), Electric current systems for polar substorms and their magnetic effect below and above the ionosphere, Radio Sci., 6 , $269-275$

Fukushima, N. (1976), Generalized theorem for no ground magnetic effect of vertical currents connected with Pedersen currents in the uniformconducting ionosphere, Rep. Ionos. Space Res. Jpn., 30(1-2), 35-40.

Galand, M., and A. D. Richmond (2001), Ionospheric electrical conductances produced by auroral proton precipitation, J. Geophys. Res., 106(A1), 117-126

Green, D. L., C. L. Waters, B. J. Anderson, H. Korth, and R. J. Barnes (2006), Comparison of large-scale Birkeland currents determined from Iridium and SuperDARN data, Ann. Geophys., 24, 941-959.

Greenwald, R. A., et al. (1995), Darn/SuperDARN: A global view of the dynamics of high-latitude convection, Space Sci. Rev., 71, 761-796.

Haines, G. V. (1985), Spherical Cap Harmonic Analysis, J. Geophys. Res., 90(B3), 2583-2591.

Hardy, D. A., M. S. Gussenhoven, and E. Holeman (1985), A statistical model of auroral electron precipitation, J. Geophys. Res., 90, 4229-4248.

Hardy, D. A., M. S. Gussenhoven, R. Raistrick, and W. J. McNeil (1987), Statistical and functional representations of the pattern of auroral energy flux, number flux, and conductivity, J. Geophys. Res., 92(A11), 12,27512,294 .
Inhester, B., J. Untiedt, M. Segatz, and M. Kurschner (1992), Direct determination of the local ionospheric hall conductance distribution from two-dimensional electric and magnetic field data, J. Geophys. Res., 97(A4), 4073-4083.

Lummerzheim, D., M. H. Rees, J. D. Craven, and L. A. Frank (1991), Ionospheric conductances derived from DE-1 auroral images, J. Atmos. Terr. Phys., 53, 281-292.

Ostgaard, N., J. Stadsnes, J. Bjordal, R. R. Vondrak, S. A. Cummer, D. L. Chenette, G. K. Parks, M. Brittnacher, and D. L. McKenzie (1999), Global-scale electron precipitation seen in UV and $\mathrm{X}$ rays during substorms, J. Geophys. Res., 104, 10,191-10,204

Ostgaard, N., J. Stadsnes, J. Bjordal, G. A. Germany, R. R. Vondrak, G. K. Parks, S. A. Cummer, D. L. Chenette, and J. G. Pronko (2001), Auroral electron distributions derived from combined UV and X-ray emissions, J. Geophys. Res., 106, 26,081-26,090.

Press, W. H., S. A. Teukolsky, W. T. Vetterling, and B. P. Flannery (1986), Numerical Recipes in Fortran 77: The Art of Scientific Computing, 2nd ed., Cambridge Univ. Press, New York.

Raeder, J., et al. (2001), Global simulation of the Geospace Environment Modeling substorm challenge event, J. Geophys. Res., 106(A1), $381-$ 396.

Rasmussen, C. E., R. W. Schunk, and V. B. Wickwar (1988), A photochemical equilibrium model for ionospheric conductivity, J. Geophys. Res., 93(A9), 9831-9840.

Ruohoniemi, J. M., and K. B. Baker (1998), Large-scale imaging of highlatitude convection with Super Dual Auroral Radar Network HF radar observations, J. Geophys. Res., 103(A9), 20,797-20,811.

Ruohoniemi, J. M., and R. A. Greenwald (1996), Statistical patterns of high-latitude convection obtained from Goose Bay HF radar observations, J. Geophys. Res., 101, 21,743-21,763.

Ruohoniemi, J. M., and R. A. Greenwald (1997), Rates of scattering occurrence in routine hf radar observations during solar cycle maximum, Radio Sci., 32(3), 1051-1070.

Ruohoniemi, J. M., and R. A. Greenwald (2005), Depenencies of highlatitude plasma convection: Consideration of interplanetary magnetic field, seasonal, and universal time factors in statistical patterns, J. Geophys. Res., 110, A09204, doi:10.1029/2004JA010815.

Sheperd, S. G., and J. M. Ruohoniemi (2000), Electrostatic potential patterns in the high-lattitude ionosphere constrained by superdarn measurements, J. Geophys. Res., 105(A10), 23,005-23,014.

Untiedt, J. (1983), Auroral zone electrodynamics according to combined Scandinavian magnetometer array and STARE backscatter observations, IUGG General Assembly, Hamburg, Germany.

Untiedt, J., and W. Baumjohann (1993), Studies of polar current systems using the IMS Scandinavian Magnetometer Array, Space Sci. Rev., 63 , $245-390$.

Vasyliunas, V. M. (1970), Mathematical models of magnetospheric convection and its coupling to the ionosphere, in Particles and Fields in the Magnetosphere, edited by B. M. McCormac, pp. 60-71, Springer, New York

Waters, C. L., B. J. Anderson, R. A. Greenwald, R. J. Barnes, and J. M. Ruohoniemi (2004), High-latitude poynting flux from combined Iridium and SuperDARN data, Ann. Geophys., 22, 2861-2875.

B. J. Anderson, R. J. Barnes, and H. Korth, Johns Hopkins University Applied Physics Laboratory, Laurel, MD 20723, USA.

D. L. Green and C. L. Waters, School of Mathematical and Physical Sciences, University of Newcastle, University Drive, Callaghan, NSW 2308, Australia. (david.lindsay.green@gmail.com)

A. J. Ridley, University of Michigan, Ann Arbor, MI 48109, USA. 